\title{
PARKOUR AND RECREATIONAL ACTIVITIES
}

\author{
Kalvis Ciekurs \\ Latvian Academy of Sport Education, Latvia \\ Rudi Zangerl \\ Swedish School of Sport and Health Science, Sweden \\ Ivars Kravalis \\ Latvian Academy of Sport Education, Latvia \\ Žermēna Vazne \\ Latvian Academy of Sport Education, Latvia \\ Aivars Kaupužs \\ Rezekne Academy of Technologies, Latvia
}

\begin{abstract}
Recreation philosophy is human ability to relax applying various games and activities, where a game or activity has some purpose, which we should know and understand how to achieve it. Parkour is a movement, form of training, a way of getting it, the art of moving from point $A$ to point $B$ with your own body as a means in as fast, efficient and controlled manner as possible based on your own circumstances. It is completely free from competitions, competitions or other forms of rivalry. Recreation is for people to restore from everyday work routine and stress. Practically people perceive this essence of recreation which gives us a possibility to relax and creates emotions of happiness. Parkour is an art that helps you pass any obstacle to go from point A to point B using only the abilities of the human body. One of recreation and parkour kinds is outdoor activities, which means different open-air activities in nature. Outdoor activities have a physical, mental, emotional and even educational effect on a participant. Recreation and parkour activities are not organized like competitions, to participate in them there are no rules made. People who go in for recreation outdoors need only space on the land, water or in the air. It is an activity which allows an individual to renew interacting with the nature in cities and villages, as well as in virgin nature territories. What separates them from parkour is that they contain more acrobatic and spectacular movements and where there may be an assessment in the performance. Recreational activities and parkour activities have many symbioses, sometimes we can Sayed recreational parkour (parkour of basics) for everyone. We are getting great emotions and physical well-being.
\end{abstract}

Keywords: parkour, recreation, outdoor activities.

\section{Introduction}

Recreation philosophy is human ability to relax applying various games and activities, where a game or activity has some purpose, which we should know and understand how to achieve it. Recreation is for people to restore from everyday 
work routine and stress. Practically people perceive this essence of recreation which gives us a possibility to relax and creates emotions of happiness. However, if any activity or game does not seem exciting or seems dangerous, the aim of the activity is not achieved, and happiness is not gained when the activity is over. In such a case recreation activity should be chosen in the way they correspond both individual and group interests.

Parkour is a movement, form of training, a way of getting it, the art of moving from point A to point B with your own body as a means in as fast, efficient and controlled manner as possible based on your own circumstances. It is completely free from competitions, competitions or other forms of rivalry. The aim is that the practitioner learns to get past all kinds of obstacles - physical as mental. The aim of this study was to find out common features of recreation activities and parkour.

\section{Theoretical background}

The notion recreation has come from the Latin language and means restoration, although it is understood as the renewal of physical and mental work capacity (Getin, 2011). Nowadays there are various explanations of the notion recreation:

- $\quad$ recreation is restoration after work and everyday duties achieved by different entertainment, games and activities;

- $\quad$ recreation is any means of body and mind renewal;

- recreation is any activity performed by human in his/her leisure time.

One of recreation kinds is outdoor activities, which means different open air activities in nature. Outdoor activities have a physical, mental, emotional and even educational effect on a participant. Recreation activities are not organised like competitions, to participate in them there are no rules made. People who go in for recreation outdoors need only space on the land, water or in the air (Kari, Michael, \& Duane, 2013). It is an activity which allows an individual to renew interacting with the nature in cities and villages, as well as in virgin nature territories. Outdoor recreation can be divided into:

- On resources-oriented recreation, where nature is the most essential and integral part of recreation experience. Recreation activities mostly are held in open air near rivers, lakes, sea, in marshes, woods, meadows, special nature places (national parks, reserves, restricted areas, etc.), etc.

- Inter-stage recreation is held in natural environment, but with people's effect. Usually inter-stage recreation is held in national and regional recreation territories, national parks, in comparatively easily reachable nature places. 
- $\quad$ To user-oriented recreation, what takes place mostly in cities - in urban environment, where nature is like a scene giving background effect rather than real use of nature.

Outdoor activities are available both in summer and winter and include various kinds of sport and activities, encompassing several sports or none of sports. People like being outside because their work is mostly inside, thus recreation outside can keep human's emotional, psychological and physical body in balance and harmony. Participating in different recreation activities having physical character, human's self-image and self-confidence is developed. Recreation activities can be divided into cyclic (skiing, Nordic walking, cycling, skating, running, walking, swimming, etc.) and acyclic movements (sport games, gymnastics, martial arts, parkour, wakeboard, Alpine skiing, etc.) (Bell, 1997).

When choosing different recreation activities unconscious "model" forms which direction each of us chooses to go. It makes a total individual's image or lifestyle in all its expressions. Each of us wants to relax from everyday routine, applying active physical activities (walk), passive activities (going to the theatre), and remedial activities (spa) where not only mental and physical body harmony is renewed, but also health is improved (Forsberg, 2014). All recreational activities outside work and everyday stress develop an individual such as we see him/her in leisure time, and it also determines lifestyle guidelines which one chooses to follow in his/her free time.

Lifestyle determines the way of thinking both at work and recreation activities, and it is a direct reflection of one's lifestyle in order to achieve the pinnacles of happiness, and each of them has different directions and wishes. Lifestyle develops under the influence of other people around, it develops already from childhood when one's parents and siblings played inside or outside, and developed movement skills and abilities, when various recreation activities and aims were given, thus also acquiring further life skills for work and leisure. Parents and the closest family members determine one's thinking direction both in childhood and later, however, later friends play an essential role in choosing recreational activities. School provides children and adolescents with a possibility to develop and affects them both positively and negatively what determines in which way children and adolescents will choose recreational activities, where they will feel well and enjoy them.

Parents, relatives, friends and other people around affect one's selfconfidence which starts developing already in childhood and to a great extent also determines one's further life perception, style and the way of thinking. Selfconfidence also determines one's choice to do a definite recreational activity. The higher the self-confidence is, the bigger the possibility that active and even dangerous activities are chosen, the lower the self-confidence is, activities not 
linked with high physical activity which do not require great physical, emotional and mental contribution are chosen.

Self-confidence gives us the possibility to prove ourselves and be happy about the chance to do what we like, thus we become more tolerant and kinder in communication with others and ourselves. It develops a harmonious environment around us, creating a positive energy which in its turn affects positively more and more people who also do physical recreational activities. Recreational activities affect positively our physical, mental and social aspect.

Depending on the intensity and dynamism of a recreational activity people search for the most suitable sport, activity or game for themselves. What an individual chooses is his/her basic motivation need for comfort, involving spiritual, physical, mental, intellectual and social satisfaction. Thus, not only an easily enjoyable entertainment is obtained as a result of motivation, but sometimes it requires a great effort where the chosen activity is difficult, complex, even painful and causing adrenalin. Recreation activities are of different character, and each of us chooses such an activity which attracts more and more people, because it does not require a definite end result opposite to different competitions. Competitions include definite regulations and rules which should be observed by everyone, however, recreation activities can contain or not contain definite regulations, as well as rules which are characteristic to competitions are not strictly stated and observed.

Nowadays extreme adventures take an essential role in the area of recreation activities, causing challenge both individually and in group. Thus experience of different level is achieved causing adrenalin during recreation activities. Experiencing something new and extreme sense of fear might be overcome, and one can see oneself from a new side. By increasing recreational activity amount and making them different, we can test ourselves what we are able to do, and it gives us joy and happiness. Learning something new, we prove ourselves that we are able to do that, thus increasing self-confidence and motivation to continue and try something new, challenging ourselves to new achievements.

In recreational activities nature resources are regularly used as the activity venue, however, not always people respect resources given by nature. People's effect on nature can be direct and indirect but being aware of what we leave behind us it is possible to take care of, learn and respect nature more, which is the purpose of sustainable interaction basis. Thus, balance is provided in nature and harmony among people, as well as respect towards all around us. We could characterize the essence of recreation activities in the following way - to have a joy to be happy, but to listen to others and oneself by taking care of everything what is around us for our descendants could enjoy the beauty of what is given by nature like us. 
"Parkour is an art that helps you pass any obstacle to go from point A to point B using only the abilities of the human body" David Belle. Parkour can also be described as the art of escape and the art of reaching (Angel, 2011).

Today we can talk about different forms of parkour with names like; Free running, tricking, street movement, etc. What separates them from parkour is that they contain more acrobatic and spectacular movements and where there may be an assessment in the performance. This means that it becomes a more ineffective mode of movement. All of these types of training are still gathered today under the parkour concept. The important is not the names, but one finds their individual way of moving. Although parkour is a free exercise form, there are some basic techniques that are important where the movement is adapted to a certain type of obstacle. It is about being able to reduce and utilize forces in a functional manner, such as being able to dampen the forces in a downfall / fall or to be able to use forces in different directional changes to get along or pass different obstacles.

To start with parkour, there is no special prerequisite but to get well in parkour it takes a long time. A lot of basic and basic training is required to build up a versatile operating competence. On the organized parkour exercises, a lot of time is spent on this basic training in terms of mobility, strength and all-round exercise for the whole body. Strictly, it is about building a good relative strength, is strength in relation to its body weight, in order to carry up its body. This exercise is important in order to achieve the purpose of being able to move fluently and make all maneuvers flow into a smooth motion. Training is therefore based on speed, stamina, strength, mobility, balance and precision. What largely characterizes a good technique / agility and control as well as mastery of their body in motion is when the move is done almost silently - "smooth as a cat". Achieving this also means that the move is energy-efficient / economically viable. The movement takes place with well-balanced power effort and you do not consume unnecessary power and energy. Although this movement takes place without spectacular acrobatic moments, the movements can be perceived as aesthetically beautiful.

Summary benefits that we want to mention are (Edwardes, 2009);

- Requires no expensive equipment.

- $\quad$ Fits all because there is no right or wrong. You are free to do what you want within your own limits. Everyone has an intrinsic willingness to move.

- $\quad$ No form of competition and there are also no governing rules. Slips others' assessment. In such a case, the driving force is to compete against itself. Support each other instead of defeating each other.

- The training is versatile and builds a versatile operating competence and basic strength. Developed body control can also enhance self-esteem 
and grow as an individual. The versatile operating competence also means that it can be easier to participate in social games and games as well as enter into other social contexts.

- $\quad$ Never get tired because there are always new challenges and new skills to learn. Exit only from yourself and create your own challenges and your own training methods.

- It involves many different learning processes in which the practitioner sees and teaches (positive idols / role models), self-seeking knowledge, companionship, fader roles, etc. It may, for example, be about behavior and approach. Practitioners are also included in creative discussions about new ideas, including security, and which result in an experimentation where they find new moves / challenges. They also seek inspiration online.

- Controls and develops by themselves / youth culture without the involvement of adults.

- When young people meet to exercise parkour exciting things will arise in the meeting. It will be an exciting meeting place both socially and in exchange for experiences. They often look up each other and create contacts through social networking on the internet. The communication also takes place over generational boundaries. From the internet, information is also gathered or agreed upon for acupuncture / "jam".

- $\quad$ Parkour can also be available and create challenges for people with disabilities.

For the practice of Parkour, nothing really requires more than most people wear every day. It's even preferable since everyday clothes are the most likely clothes you will wear when you need parkour. However, when you know that you are going to work out, you can simplify the clothes you are wearing. However, the most important thing is the shoes. Given the running and landings that the training usually means, grime-friendly shoes with some dampening effect are recommended. Grip-friendly shoes are of course also linked to increased safety / not to slip. Helmets, shelters and the like are not recommended as it limits both mobility and the fact that it goes too fast. Control and safety in the exercises are gradually being built up to completion. The limited equipment requirement makes parkour available to all, since no expensive special equipment is required (Thibault, 2012).

In terms of safety, many people ask whether it is dangerous to practice parkour. Within parkour, the basic philosophy of safety is that every person is based on himself and his own skills. It is therefore important to not be too peppered or pushing each other / someone else to do things that are not ready for. A good quote, from Martin Svenselius founder of the Stockholm Parkour 
Academy, describing this is; "We do not train our movements just to be able to do them, we train them to make it impossible for us to fail." There are no shortcuts in terms of safety. The goal is to be able to exercise all life without long-term unnecessary wear and tear and short-term damage. Today, children and adolescents see very extreme parkour with heartbreaking and life-threatening stunt in action films, and they seek and tip each other about "cool” movie clips on the internet, for example, jumping between high rooftops. This may cause them to be affected and may be misrepresented by parkour. In connection with this we also want to pick up the choice of "arena / training area" for their exercise and training. All practitioners, like anybody, must respect private areas or areas where the surrounding area is disturbed. Today, parkour facilities are being built, both indoors and outdoors, which of course is a safer place to start practicing parkour than it is in urban environments. The facilities have subdued falls under high barriers and are therefore a perfect meeting place for beginners and suits all ages. Here we see that the teachers in sports and health around Sweden's schools become important "ambassadors" to spread this safety philosophy as well as what consideration should be given to the choice of "arena" and advocated in the parkour movement.

\section{Methodology}

This study is of theoretical character, summarizing theoretical features of the recreation activity area and parkour area. In the study opinion by different authors about what is recreation and parkour, and what are their activities is looked at. According to the found out materials which reveal the essence of recreation and parkour, as well as personal experience, the map of recreation and parkour activities was made, that affects participants doing these activities. Cognitive, social and physical features and sensations are fixed in this map.

\section{Results}

As we see in the text above there are many similarities between Parkour and recreational outdoor activities. Both have the purpose to develop the individual and social personality. 
Ciekurs et al., 2020. Parkour and Recreational Activities

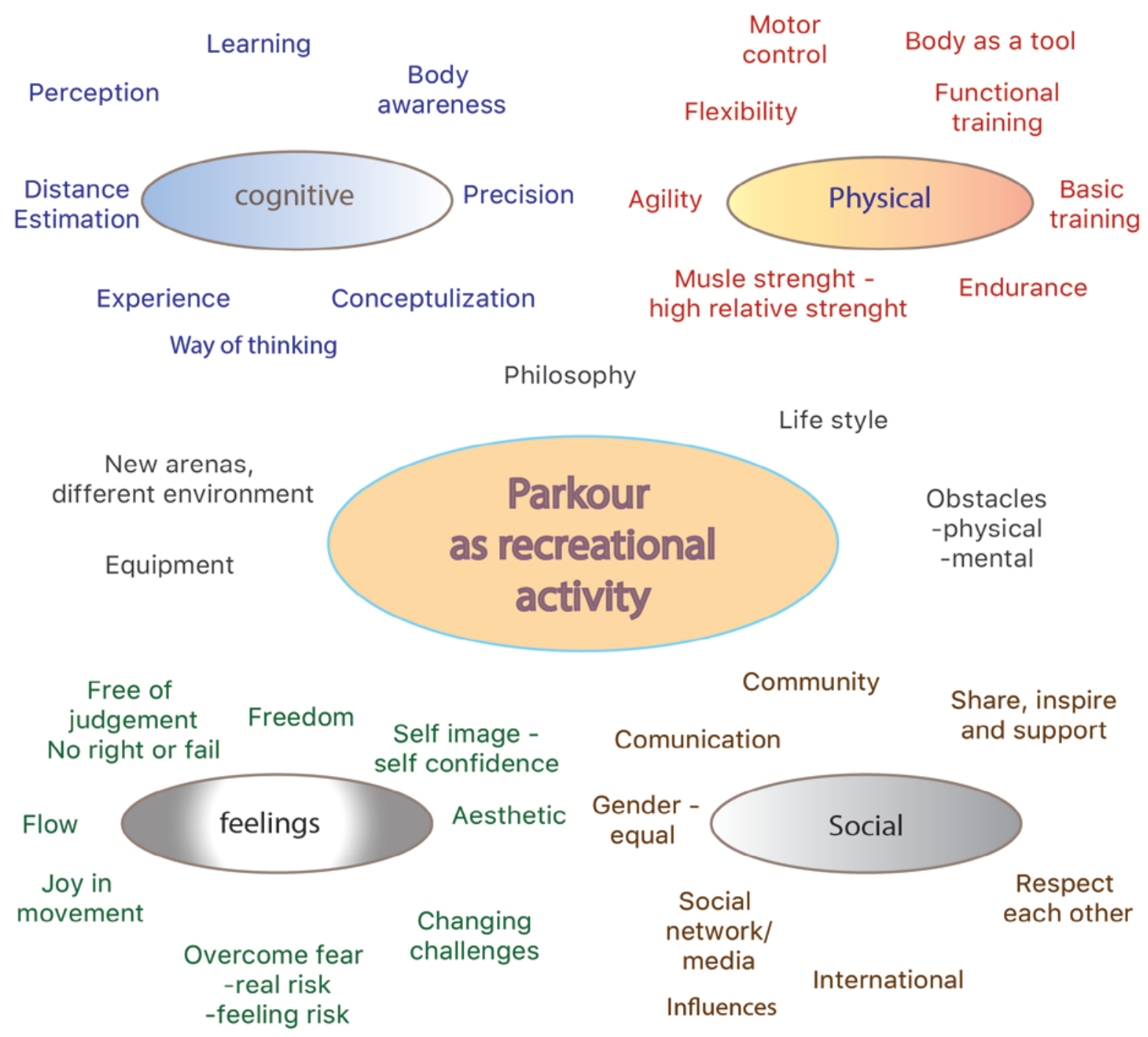

Figure 1 Parkour as recreational activity

We can look at that in a didactic way and with different perspectives (Figure1):

Physical perspective:

Body as a tool - you own your body and develop it by training, be kind to your body;

Basic training - means that you train the basic qualities as endurance, balance, flexibility, muscle strength mostly in relation to your body weight and agility;

Functional training - to train movements you use in your daily life;

Motor control - to develop and increase your coordination between muscle groups.

Cognitive perspective:

Learning processes - through experiencing; 
Body awareness, perception, distance estimation and precision are mental qualities which getting trained during exercise;

Conceptualization - means to know right terms, understand cause and effect and categorize.

Affective perspective - feelings:

Self-image and self-confidence - if its high and positive you feel good;

Joy in movement - the most important motivator;

Overcome fear - face your fears which prevent you from trying and training new movements and situations, the real risk (risk for injuries) shall be low while the experienced risk should be high; this in relation to finding new challenges;

Freedom - feeling to be free, to go your own way, not to be controlled or judged by others;

Flow - feeling that every movement is easy, you are moving quietly and with full body control and experiencing the aesthetic part of the moving body in the environment.

Social perspective:

Gender equal - there are the same possibilities and conditions for man and women to do recreational parkour;

Social network - in the beginning of parkour in the early 2000 the internet was exploding, and practitioners met each other and communicated via Facebook and nowadays Instagram, twitter, snapchat etc., they organized meetings/jams by contacting via internet;

Community - in a group of people with the same goals and purposes it is easier for individuals to develop physical and social skills, to feel confident especially if the atmosphere is secure and the policy is to take care of and respect each other.

\section{Discussion}

When is parkour getting / becoming recreational? More often and often scientists today do research that is directly linked to spending our free time outside working hours. But less attention is paid to parkour activities in leisure time, although parkour plays more and more significant role in teenagers and adolescents' free time. However, there are scientists like (Mclean \& Hurd, 2015) who have studied the relation between recreation and parkour, how parkour can be used in the offer of recreation activities (Turner \& Carnicellli, 2017) have taken a look at parkour as a new kind of recreation, perceiving parkour as a nontraditional physical activity, although nowadays it could be understood as selfevident (Robert, Wells, \& Banning, 2016) have studied recreation, sports activities, including parkour. Having studied the authors' research, we can assume that parkour which is not directed towards competitions and observing of the rules 
and recreation which gives a possibility to get rid of everyday routine can be a great means to facilitate mental and physical relaxation. It should be emphasized that recreative parkour is done by teenagers and adolescents, and nowadays it is pointed out that sports activities of various degree of difficulty should be chosen without any limits.

\section{Conclusions}

Recreation involves improvement of physical and mental work capacity by doing different activities which improve participants' emotional, mental and physical condition.

Parkour includes movement freedom, the effectivity of movement execution that allows participants to express themselves creatively and gives positive emotions improving also one's physical condition

Recreational activities and parkour activities have many symbioses, sometimes we can Sayed recreational parkour (parkour of basics) for everyone. We are getting great emotions and physical well-being.

\section{References}

Barcelona, R.J., Wells, M.S., \& Arthur-Banning, S. (2015). Recreational Sport: Program Design, Delivery, and Management. Human Kinetics.

Bell, M. (1997). The development of expertise. Journal of Physical Education, Recreation \& Dance, 68(2), 34-38.

Edwardes, D. (2009). The Parkour and freerunning handbook. iTBooks.4.

Herrmann, J. (2016). Parkour/freeruning as a pathway to prosocial change: a theoretical analysis. Victoria university of Wellington. Thesis.

Petersson-Forsberg, L. (2014). Swedish spatial planning: A blunt instrument for the protection of outdoor recreation. Journal of Outdoor Recreation and Tourism, 5, 37-47.

Gentin, S. (2011). Outdoor recreation and ethnicity in Europe-A review. Urban Forestry \& Urban Greening, 10(3), 153-161.

McLean, D., \& Hurd, A. (2011). Kraus' recreation and leisure in modern society. Jones \& Bartlett Publishers.

Sundari, R. (2018). Leisure management services - a study to analyse the Market potential among the middle class consumers in chennai. International journal of engineering research and development, 14(9), 3-13.

Lepisk, P., \& Swenselius, M. (2008). Uppväxtmiljöochhälsa: Enundersökning om hälsoskillnadermellan barn iinnerstadenochförorten. Deoartment of sport and health sciences. Thesis.

Thibault, V., \& Roberts, C. (2013). Parkour and the art du deplacement: Strength, dignity, community. Montreal, Canada: Baraka Books.

Turner, D., \& Carnicelli, S. (Eds.). (2017). Lifestyle sports and public policy. London: Routledge. 